\title{
DEVELOPMENT AND IMPLEMENTATION OF A NEW CONCEPT OF CRISIS SITUATIONS SYNDROME: "SYNDROME OF A HYBRID WAR"
}

\author{
Yuriy Danyk \\ Institute of Information Technologies \\ Ivan Chernyavskyi National Defense University of Ukraine \\ 28 Vozduhoflotskiy ave., Kyiv, Ukraine, 03049 \\ zhvinau@ukr.net \\ Oleksandra Zborovska \\ Department of uveitis \\ SI "Filatov Institute of eye disease and tissue therapy NAMS" \\ 49/51 Frantsuzskiy blvd., Odessa, Ukraine, 65061 \\ filatov.uveitis@gmail.com
}

\begin{abstract}
The aim of our research was basis of the analysis and research of the current state and trends of emergence and development of crisis situations syndromes to identify their general and specific features inherent in specific crisis situations syndromes at the place where they occurred, factors that influenced their formation and the manifestations they characterized by.

Materials and methods - analysis and systematization of data on the complex impact of stress factors and other manifestations of crisis situations on subjects who find themselves in a zone of military conflict/man-made or natural disaster; formulation of new concepts, strategies and tactics for work in crisis situations.

Results. Common and specific features of the known syndromes of wars are found. It is proved that, by common characteristics, all syndromes of wars can be combined into a single basic category - crisis situations syndrome, which is divided by specific features into specific crisis situations syndromes at the place where they occurred, under what factors they were formed and the manifestations they characterize. A classification of post-traumatic stress disorders as a component of crisis situations syndromes by the mechanisms of their formation and a model of their formation are provided. Definitions are formulated; crisis syndrome and hybrid war syndrome are described. A working table has been developed for analysts for the differential diagnostic of "Crisis Situation Syndromes".

Conclusions. The technology of objective diagnostic, treatment and prevention of PTSD (post-traumatic stress disorder) and hybrid war syndrome is proposed, which includes the identification of possible etiological factors affecting the formation of crisis states syndromes with differentiation of impact factors, the actual identification with the formation of a differentiated approach to treatment, and prevention development of "coaching" techniques. The technology is based on a comprehensive psychological and ophthalmologic examination. It has been established that the "hybrid war syndrome" is formed both among combatants and non-combatants, for the first time in it the cognitive defeat, both of individual subjects and social groups is fully manifested. In addition, for the first time, in relation to other crisis syndromes, there are social group symptoms, the formation of migratory symptoms, the formation of specific PTSDs, etc.
\end{abstract}

Keywords: "specific hybrid war syndrome", cognitive confrontation, specific PTSD of hybrid war.

\section{Introduction}

War accompanied mankind throughout its existence. Herewith, world history shows a clear trend of increasing their number. Thus, for example, over a period of 15 years - from the end of the 19th century until the First World War (1914-1918), 36 wars and military conflicts were recorded ( 2.4 wars per year). In a hundred years for the same period, 100 (10 conflicts per year) were recorded [1].

At the beginning of 2017, according to the American Center for Comprehensive Peace (CSP), almost four dozen wars and military conflicts took place on Earth, in which 28 countries took part. Of these, almost half (13 countries) had protracted conflicts, such as lasting more than 10 years. These are Afghanistan (36 years old), Colombia (39 years old), Democratic Republic of 
Congo (22 years old), India (62 years old), Iraq (34 years old), Myanmar (66 years old), Nigeria (17 years old), Pakistan (17 years old), Philippines (42 years), Somalia (26 years), Sudan (31 years), Turkey (30 years) [2].

The peculiarity of wars and military conflicts of modernity was the manifestation in the majority of their participants and those who found themselves in the zone where they occur, the characteristic specific symptoms, which are associated with the complex effect on them of physical, psychological, informational and other factors of war. Initially, mental disorders caused by traumatic events and stressful situations, which (after the events of the Vietnam War) were called post-traumatic stress disorder (PTSD), were considered the main cause of such a state by the participants in the events. But participants in crisis situations (wars, armed conflicts) that took place in the future, along with PTSD, already appeared others characteristic symptoms that only caused them to reasonably differentiate the syndromes by the place where the events took place and by factors affecting the participants these situations ("Vietnamese syndrome", "Persian Gulf syndrome", "Afghan syndrome", etc.).

One of the worst manifestations of the development of these syndromes were suicides and acts of unmotivated aggression directed against other persons. According to statistics, after returning from the Vietnam War, three times more of its participants committed suicide than were killed in it, the same thing happens with participants of other wars (military conflicts) that occurred after the Vietnam War.

From one crisis situation to the next, the syndromes of these crisis situations become more complex, more multifaceted, multisymptomatic, and multisystem. Such symptoms in several other manifestations also occur in non-combatants who are in the combat zone. Moreover, similar syndromes occur in many individuals who find themselves in the zone of any crisis situations (zones of modern military (armed) conflicts, man-made or natural disasters, places where terrorist acts took place, etc.).

Therefore, a study of the causes, characteristics of the development of crisis situations in general and specific crisis situations at the place where they occurred, the factors that caused their formation and/or the events that caused them, the manifestations that characterize them and the problems of overcoming them is relevant and important.

For the first time the term "...war syndrome" appeared in the United States after the end of the Vietnam War (1965-1975). Most researchers identify the "Vietnam War Syndrome" with post-traumatic stress disorder (PTSD) [3; 4]. In 1980, the scientist M. Horowitz singled out post-traumatic stress disorder (PTSD) as a separate nosological form of mental disorder [5].

The Vietnam War has become a powerful incentive for research by American psychiatrists, psychologists and other specialists [6]. At the beginning of the Vietnam War, it was reported that the number of soldiers with combat mental trauma in comparison with other American wars was insignificant. This was explained by the lack of long-term shelling, the replacement of personnel every 12 months, the sporadic nature of the fighting, with frequent breaks for rest. Then it was announced about the successes of military psychiatry and optimism was expressed that "psychiatric losses will never again become the main cause of the depletion of resources of US troops in the combat zone." However, after a while, the widespread prevalence of combat mental trauma with a different psychopathology, "unconventional" for previous wars, manifested itself. Its typical features were regressive symptoms with a delayed onset, experiencing guilt, aggressiveness, dissocial behavior, and drug abuse [7].

In the DSM - III (1980) (Diagnostic and Statistical Manual of Mental Disorders), the American Psychiatric Association summed up the author's definitions of "survivor syndrome", "Vietnamese syndrome", “delayed stress", etc., using official diagnostic criteria for post-traumatic stress disorder (PTSD) [7].

They are: the presence of an extreme event (wound, the presence of dead comrades or the enemy, fear when hit by shelling, etc.); repetitive and intrusive memories and replay in the minds of an event or a series of events that caused mental trauma, obsessive experiences with nightmarish dreams; the desire to avoid situations associated with the experienced; amnesia of certain aspects of the experienced and/or persistent symptoms of increased psychological excitability: dysomnia, 
irritability, difficulty concentrating, alertness, enhanced reflex of the quadrigeminal (quick turns of the head and eyes with auditory and visual stimuli) [7]. Sometimes they hang so heavy that they blur the line between reality and memories. As a result, there is a presence of the exhausting constant vigilance and anticipation of the threat [8]. Therefore, any sharp stimulus can cause an inadequate reaction $[9,10]$. Studies of PTSD have shown that it can manifest itself immediately after a traumatic event or lead to negative long-term symptoms and show symptoms sufficient for the diagnosis of PTSD (or associated with it) years later [10, 11]. According to the researchers, PTSD of varying degrees of severity had up to $60 \%$ of veterans of the Vietnam War $[12,13]$.

A similar situation, as with the "Vietnamese syndrome", has developed in the former USSR and the countries of the former Soviet Union after the war in Afghanistan (1979-1989). Most of the participants in the war who returned have received some degree of PTSD.

According to the estimates of researchers, Chechen Syndrome (1994-1996) was similar to Vietnamese and Afghan ones (1979-1989) [14], but different from the Chechen Syndrome (1999-2009).

At the same time, although the terms PTSD and "syndromes of ... wars" in Vietnam (19651975), in Afghanistan (1979-1989) and Chechnya (Ichkeria) (1994-1996) are considered almost identical, the essence of their formation and the characteristics of the manifestations led to their differentiation as independent syndromes. Each of them has specific features and differences, and is not limited to the manifestation of the participants in these crisis situations only PTSD [4].

A new round of exacerbation and the manifestation of significant specific qualitative and symmetrical differences between military syndromes have occurred since the Gulf War. After the Gulf War, the term "...war syndrome" acquired a different character and began to imply not only PTSD, but also chronic multisymptomatic disease (CMD), which does not exclude, but complements PTSD. This term is applicable to both veterans of the Gulf War (1991) and Iraq (2003), Afghanistan (since 2001).

A large number of war veterans in the Persian Gulf (1991) reported on a variety of symptoms that began during or shortly after the war. In many cases, these symptoms persist up to the present. These symptoms include fatigue, musculoskeletal pain, sleep disorders, cognitive dysfunction, and mood swings [15]. A combination of health problems, commonly referred to as the Gulf War Syndrome, affected at least one third of war veterans from countries that formed coalition forces, including the United States, the United Kingdom (Great Britain), Australia, Canada and Denmark [15]. Data on the possible number of victims of the aforementioned disease among the Iraqi population (both the civilian population and the military) is not given.

In 1998, the United States Congress passed two laws on the health of war veterans in the Persian Gulf: PL 105-277, the Persian Gulf War Veterans Act, and PL 105-368, the Veterans Programs Enhancement Act. In accordance with these regulations, the National Academy of Sciences of the USA (NAS) initiated a study of the Gulf War Syndrome, conducted on the basis of the Institute of Medicine (IOM) [16].

Considered a variety of agents that can lead to the appearance of such symptoms, including: the effects of oil burning products (oil fires [17, 18], organic phosphorus toxicants (OPT), organic phosphorus insecticides [19], drugs used for OPT prevention [20], infectious diseases [21], post-traumatic stress disorder [9] and others.

However, it was not possible to clearly define the causes of the Gulf War Syndrome. Animal experiments also did not reveal the mechanism that led to the Gulf War Syndrome [22].

As a result, the following conclusions about the syndrome of the Gulf War [22] were formulated.

Persian Gulf syndrome is not only a psychosomatic illness, although many symptoms (eg, fatigue, gastrointestinal problems) are due to psychological causes, such as depression or PTSD. However, most studies have excluded purely psychological aspects of the disease of the Gulf War. Gulf Disease affects virtually all body systems: the central nervous system, the gastrointestinal tract, the heart, the liver, the immune system, the endocrine system (thyroid, adrenal glands, pituitary, gonads), bones and skin. No mechanism explains the many symptoms found in the Gulf War Syndrome. One final agent has not yet been identified, which is its cause. 
As for the war in Afghanistan (USA since 2001), the consequences for its participants also turned out to be quite complicated. Francesco Tortora in a material published on the website of the newspaper Corriere della Sera writes: "50 \% more suicides among American servicemen than those killed in battles with the Taliban. The number of suicides in the US military over the past decade was a record one. Most of those who settled scores with life, served in Afghanistan. In the first 155 days of 2012, 154 US troops committed suicide: an average of one suicide per day. The largest numbers of suicides are among those who have several years of engagement in hostilities. However, the majority of the soldiers who decided to die were never at the front line. The reasons for suicide are prolonged stress due to prolonged stay at the front, post-traumatic problems, excessive medication and a weak American economy, unable to provide work for veterans who returned home" [23].

Thus, the authors point out a number of significant aspects. Namely: a significant part of the servicemen who decided to die was never at the forefront, excessive use of drugs by participants in the events, the specific perception of their society and the negative informational influences they suffered, their social problems.

One of the essential features of the Vietnam War Syndrome, which experts note, is the "delayed" onset of its occurrence after the return of servicemen to their homeland (delayed manifestation - when symptoms begin at least 6 months after the action of the stress factor). The same essential features of the "Gulf Syndrome", was the emergence of their symptoms during the events of the Gulf War (1991). The same is true of war veterans in Afghanistan (since 2001) and in Iraq (2003).

It should be noted that the symptoms currently associated with PTSD and other similar specific symptoms were observed in veterans of almost all wars and military (armed) conflicts: World War II, Korean War, Vietnam War, Afghan Wars, Chechen Wars, wars in Iraq and etc. However, they began to purposefully study and differentiate them after the Vietnam War (1965-1975).

At the same time, there is an interesting feature in the manifestation of symptoms, which later became known as PTSD from World War II veterans from Germany and the countries of the Anti-Hitler Coalition. To the greatest extent such symptoms manifested themselves in the Wehrmacht soldiers who fought on the Eastern Front. In the United States, after the Second World War, veterans also noted a surge in such symptoms and an increase in the number of suicides. To a much lesser extent, this was manifested in the soldiers of the Anti-Hitler Coalition, who liberated their countries from invaders. Thus, for example, in the former USSR, the trend for a substantial increase in the number of suicides in the postwar period was practically not observed. This can be judged by the data on the level of suicides among the urban population, given in [24]: 1935 - 5158, 1936 - 7140, 1937 8048, 1938 - 7678, 1939 - 7096, 1940 - 6800, 1941 - 4538, 1942 - 3462, 1943 - 4154, 1944 - 4167, 1945 - 5050, 1946 - 5424, 1947 - 7897, 1948 - 6339, 1949 - 7706. That indicates a significant role in the formation and manifestation of PTSD information-psychological and social aspects.

The characteristics and complexity of the manifestations of syndromes and the course of related diseases varied from one crisis situation to another. But, at the same time, a number of symptoms, as well as factors leading to their occurrence, as the analysis showed, were inherent in all known syndromes. At the same time, despite a fairly large number of various publications on issues related to crisis situations syndromes, their symptoms and manifestations, the problems of system analysis of a variety of factors influencing their formation, identifying the underlying causes of their occurrence and the objectivity of their detection and diagnosis remain open and require their study.

\section{The aim of the article}

Based on the analysis and research of the current state and trends of emergence and development of crisis situations syndromes, identify their general and specific features inherent in specific crisis situations syndromes at the place where they occurred, the factors that influenced their formation and the manifestations they characterize.

\section{Materials and methods}

Analysis and systematization of data on PTSD in various syndromes: Vietnam War Syndrome, Afghan War Syndrome, Chechen Syndrome, Persian Gulf Syndrome, mental disorders of 
the combatants/non-combatants during and after World War II. Analysis and systematization of data on the characteristics of human exposure in modern conditions. The authors investigated the conditions of occurrence, developed and described the mechanisms and models of PTSD emerging in a hybrid war. On the basis of the performed analysis, the formulation of new concepts, strategies and tactics for work in crisis situations was carried out.

\section{Results}

Studies have shown that the emergence and formation of crisis syndromes depends on a sufficiently large number of various factors, conditions and circumstances. They were studied, summarized and systematized by the authors.

First, in all previously occurring syndromes, the first generalizing factor in the development of syndromes was the time and place where the crisis situation occurred, of course, with its geographical and territorial features, features of the population living in the territory, etc.

Secondly, the nature of the crisis influenced the formation of syndromes. For example, the nature of war. What type and intensity of conflict, with which adversary did you have to fight, with what means of armament and military equipment (AME), what were its results?

Third, the formation of syndromes is significantly influenced by social, demographic and other characteristics of the personnel, their awareness, education, training, motivation, etc.

Fourthly, the causes and nature of the defeat of the personnel (combat physical trauma, combat mental trauma, defeat friendly fire, their own used weapons of military equipment, informational injury, etc.).

Fifth, manifestation symptoms of syndromes (PTSD, CMD, etc.).

Studied and researched the main factors and symptoms were summarized by the authors in the differential diagnostic table "Crisis Syndromes" (Table 1).

Table 1

System of differential diagnostic table "Crisis Situation Syndromes"

\begin{tabular}{cccc}
\hline No. & Factors affecting the occurrence, formation and development of the syndrome & Presence \\
\hline 1 & 2 & 3 \\
\hline
\end{tabular}

I Features of a crisis situation

1 The time and place where the crisis occurred, features of the epoch, geopolitical and local situation, geographical and territorial features ("uncomfortable and aggressiveness" of the territory: own/foreign country, geographical features (forest, field, mountains, desert, jungle, etc., urbanized areas, equipment of the zone (region) of actions), characteristics of the local population and population density, socio-economic features, etc.

2 The nature of war: low-intensity, medium-intensity, high-intensity, positional, focal, highly mobile

3 Type of army: mass armies, contract armies, private military corporations

4 The course and outcome of the conflict

II Participants

1 Participants: national, multinational, coalition armed forces, private military companies, volunteers, partisans, terrorists

2 Contingent: social origin and condition, demographic and other characteristics of personnel, their awareness, motivation, education (higher/secondary), special military education, training

3 Ratio: civilians/combatants/other categories

4 The nature and characteristics of the enemy: motivated, brutal, uncompromising, well prepared, well equipped, other

5 The ratio of personnel involved in various activities and the organization of their recreation

6 Specialty features, tasks and functions performed 


\begin{tabular}{ll}
\hline $\mathbf{1}$ & \multicolumn{1}{c}{$\mathbf{2}$} \\
\hline 7 & $\begin{array}{l}\text { Personnel involved in information and analytical activities, working with means of displaying information, } \\
\text { management, use of robotics }\end{array}$ \\
8 & $\begin{array}{l}\text { Participant's history of hitting / participation (voluntary or not) in crisis situations of various types (war, } \\
\text { military conflicts, etc.), taking into account the intensity of events in a crisis situation }\end{array}$ \\
9 & $\begin{array}{l}\text { The participant's desire to return to the crisis zone yes/no, with a description of the targets of the voiced } \\
\text { solution }\end{array}$
\end{tabular}

\section{Applied technique (weapons)}

1 Armament and military equipment: the use of weapons of mass destruction, conventional weapons of military equipment, the prevalence of non-selective destruction (areal) or high-precision weapons, information-cognitive defeat means, high-tech means

2 The use of non-kinetic weapons: quantum-optical, weapons of directed energy, electronic, etc.

3 The use of innovative and little-known means (by the enemy, their own)

\section{Features of the defeats of the participants}

1 The nature of physical lesions (combat physical injuries): contusions, abdominal injuries, amputations, sensory organs (vision, hearing)

2 The nature of mental damage: combat mental injury, non-combat mental injury (alarming expectations, accumulated stress)

3 The nature of information, cognitive, cyber influences (information-psychological, cognitive and cyberinjuries)

4 Defeat with enemy's / own weapon

\section{Medical aspects and symptoms of manifestation}

1 Anamnesis (somatic and psychiatric/psychological) before participating in events

2 Family psychiatric/psychological history (presence of mental patients in the family; people who have experienced acute psychological reactions / disorders)

3 Individual's own phobias

4 Acute stress reaction

5 Combat and work stress-reaction - a wide range of physical, mental and emotional symptoms and signs (depression, fatigue, anxiety, decreased concentration / memory, excessive excitability of the nervous system, etc.). Do not pass within 4 days after the event, when other symptoms disappeared.

6 Acute stress disorder - the term includes re-experiencing, avoiding, increasing the excitability of nervous system and at least three of the five dissociative symptoms. Symptoms last more than two days, but less than one month after the injury.

$7 \quad$ PTSD re-experiencing a traumatic event, avoiding the stimuli associated with trauma, negative thoughts and mood (which was not typical for this person before the injury), increased excitability of the nervous system (uncharacteristic before the injury)

PTSD is acute (duration up to 3 months after injury), chronic (more than 3 months), delayed (debut after 6 months).

8 «Chronic multisymptomatic disease»: headaches, dyspepsia, diarrhea, prolonged pain in muscles and joints, chronic fatigue, disorders of memory and sleep, neurological problems

9 Result: suicides, asocial behavior, alcoholism, drug addiction...

$10 \%$ of development

Considering, on the one hand, the partial commonality of the formation and manifestations of various syndromes (Vietnamese, Afghan, Chechen, Persian Gulf, etc.), and on the other, some difference in the factors underlying the formation and symptomatology of these syndromes, mani- 
festations, it was defined the concept of "Crisis situations syndrome", which allows you to summarize them and at the same time emphasize the difference between them.

"Crisis situations syndrome" (wars, military conflicts, man-made, natural disasters, terrorist acts, etc.) are conditions that manifest themselves in the form of a complex of characteristic mental, psychosomatic and physiological changes that occur in a large number of subjects who find themselves in a certain time involved in the same events, processes, actions, and subjected to a combination of traumatic effects of different nature and complex information-psychological effects.

The authors identify the following models for the formation of PTSD.

lst model.

Information about wars, damaging factors in them and their dangers is available today, and everyone can familiarize themselves with it / explore this issue. The combination of the obtained amount of information about the possible consequences of participation in hostilities and their own characteristics of the intellect and psyche, phobias - especially if they correspond to the situation in which a person falls, form the so-called "pre-PTSD phase" - "pre-PTSD". Especially if this is accompanied by the presence of a situation that "modulates" a certain state. For combatants, the "pre-phase PTSD" develops, as a rule, at the stage of obtaining information about the expected participation in hostilities.

At the next stage - following to the place of concentration, the combatant increases the expectation of danger. Thus, a prerequisite for PTSD or "mild PTSD" is being formed. On the one hand, at this stage, due to the time allotted for preparation and its implementation with imitation of possible real situations, we should expect a decrease in fears and anxious expectations, on the other hand, this often leads to the opposite effect - an increase in fears.

At the next stage - arrival in the combat zone - the combatant is exposed to a whole range of traumatic factors (physical, mental, informational, cognitive) in one or another combination of one or another intensity, which ultimately can lead to the formation of an acute stress reaction / combat stress reaction / acute stress disorder. If the combatant already has a "soft" PTSD, then PTSD itself is formed as a result. Combatants can develop PTSD itself without a "mild" PTSD phase, if the intensity of the effects exceeds the individual stability of the psyche and the combatant himself and/or his entourage did not appreciate the intensity of the acute stress response / combat stress response / acute stress disorder and how the combatant copes with arising disorders. Depending on whether the combatant himself received a combat physical injury as a result of physical impacts of a different type, or these combat injuries were received by others - before his eyes, 2 types of PTSD should be distinguished. The aggravating moment is the high degree of reinforcement of the expectations of fears, in particular the fear of receiving a severe disabling injury, the fear of death, the fear of pain, the fear of injury / death of friends.

After returning from the combat zone, the development of the next phase of PTSD "aggravation" is possible due to informational influences and peculiarities of interaction with society.

Special mention should be made of other models of the formation of PTSD from UAV operators (2nd model) and military pilots who piloted aircraft (airplanes / helicopters) (3rd model). The first and second stages of the formation of PTSD in them are similar to the foregoing 1st model of the formation of PTSD. Differences with the 1st model and between the 2nd and 3rd models develop at the 3rd stage. UAV operators have a high degree of responsibility due to the cost of equipment and responsibility for the lives of other combatants, aggravated by the fear of waiting for punishment in case of loss of the device and visualization of damage and combat injuries of individuals under the influence of UAV without direct participation in hostilities (which may aggravate the cognitive dissonance between the situation in which the UAV operator is and the information he receives through the viewer the first analyzer in the knowledge of reality inflicted injuries / losses of individuals and their degree of responsibility) [6].

In military pilots in the development of PTSD also play a big role a high degree of responsibility, due to the cost of equipment and responsibility for the lives of other combatants, which is combined with fear for their own lives, fear of receiving combat physical trauma and being captured. The aggravating factors contributing to the formation of accumulated stress is the use 
of electronic means of displaying information (for example, night vision devices), which leads to an excessive load on human sensory systems and the combatant's presence in the "semi-virtual reality". Particularly aggravating factor is the fear of injury / development of PTSD, which can lead to disqualification.

It should be especially noted that new little-studied factors are superimposed on all these mechanisms described above.

The following classification of PTSD can be proposed:

1. "Shock - stressful" PTSD, both physiological and psychological, and of a mixed type.

2. "Stress accumulative".

3. Combined.

4. "Delayed stress".

The need to distinguish PTSD, obtained as a result of the conventional component and stay in a combat stop, from PTSD obtained as a result of information and cognitive influence, is becoming increasingly important. A special role should be given to the development of the "hybrid war syndrome" and PTSD in the category of highly skilled military personnel, such as serving in special units (special operations forces), reconnaissance, snipers, pilots, operators of robotic and intelligence equipment, information, psychological, cybernetic action. This category, in which there is a specific formation of PTSD (accumulated stress), is often prone to concealing its symptoms in the early stages of its formation, which can have a very negative effect on the performance of the combat mission, both individually and on a large scale. Moreover, as we indicated earlier, the "hybrid war syndrome" can develop not upon return, but directly at the moment of staying in the combat zone, and begins to form as an informational pre-PTSD even before being sent to the active zone i.e. this category of military can be on the assignment already being in an unstable mental state and have abnormal bursts and manifestations, depending on the intensity of information-psychological and cognitive influences and injuries. According to US statistics, only $40 \%$ of war participants voluntarily seek help for PTSD.

The authors have developed a version of the technology of objective diagnosis, treatment and prevention of PTSD and hybrid war syndrome. It includes:

1. Establishment of possible etiological factors affecting the formation of crisis states syndromes.

Differentiation of factors:

- by time interval of influence: acute and chronic stress impact shock stress / accumulated stress;

- by the physical / mental / informational component of the impact (conventional / non-conventional impact);

- by the presence of factors preceding the crisis. The presence / absence of education and the specifics of education, prior social phobias;

- according to the degree of responsibility and tension when in a crisis situation;

- on working with innovative tools and devices.

2. Detection. Based on the mechanisms involved in the development of the syndrome (mental, physiological, neurophysiological), the creation of an integrated assessment methodology and diagnostic algorithms (using hardware-based objective research methods of human sensory systems, an objective latent control system for psychological assessment [25]).

3. Differential treatment approach, which is based on the choice of various therapies depending on the established various etiological factors.

4. Prevention. Development of "maintenance" techniques at all stages.

Creation of an "individual base map" in order to identify possible risks of developing crisis syndromes and disorders on the part of the visual analyzer. And also with the purpose of using this map as a "point of reference" for tracking the dynamics of mental and ophthalmologic disorders at the subsequent stages. Conducted at the time of admission to a specialized military structure.

Includes two groups of studies:

1. Joint ophthalmological-psychological examination. Conducting psychological testing/ interviews in parallel with the registration of the movement of the eyeballs and pupillary reactions. 
The combination of such examinations is due to the factors that the amygdal-limbic system is responsible for the basic survival instincts, one of the obvious manifestations of which is the vestibulo-ocular reflex or the quadrigeminal reflex. For more complete information, it is possible to combine with the registration of the pulse and respiration rate.

2. Ophthalmologic examination. The study of accommodation, convergence, dark adaptation, visual fields, blood circulation of the eyeballs and electroretinography (ERG) before and after using electronic means of visual display of information for a certain period of time.

On the basis of the obtained data, it is possible to develop individual recommendations on the time and frequency of use of special electronic means of displaying information during the day, performing a set of exercises and pharmacological correction.

Second phase.

It is conducted with the passage of special training that simulates combat conditions (the formation of "vaccinations" from PTSD).

Includes the same two groups of surveys. A comparison is made with the "individual base map".

Further maintenance is carried out every 3 months when in a zone of a crisis situation or after specific events.

Conducting the same survey groups.

Provides a comparison with the "individual base map". If certain markers of the syndrome are identified during the examination, referral to a specialized institution for further examination and therapy.

\section{Discussion of the results}

Of particular importance in the process of formation and development of crisis situations syndicates, as shown by the authors of the study, are informational and psychological factors (informational and psychological actions carried out, propaganda and counter-propaganda, the work of strategic communications of one's own and the enemy, the perception of events affected and the attitude of society, their social security and comfort.

As Nash William (the navy psychiatrist who led the martial stress control program among the marines) found out - contrary to popular belief, the greatest harm to the psyche is not the fear or horror that soldiers have to overcome on the battlefield, but feelings of shame and guilt, associated with the moral injuries from which they suffer [26].

This convincingly explains why Wehrmacht soldiers who fought on the Eastern Front in World War II and those soldiers of the Anti-Hitler coalition who fought far from their countries in foreign territories suffered the most from post-traumatic stressful conditions, as well as the practical absence of such syndromes in soldiers of armies who liberated their territories from invaders and were perceived by the population of their countries as soldiers-liberators, winners, and internally felt that they were. At the same time, the solution of social issues (employment, education, social protection) played a major role.

This, with a high degree of probability, makes it possible to give an explanation of the "delayed" onset of the "Vietnam War Syndrome" and the appearance of the symptoms of the "Gulf Syndrome" already during the events of the Gulf War (1991). The same is true of war veterans in Afghanistan (since 2001) and in Iraq (2003).

First of all, attention is drawn to the growth of multisymptoms and the aggravation of the manifestations of syndromes on increasing from one conflict to another. The first officially recorded and investigated features refer to the Vietnam War, in which there was no clear motivation of combatants, combined with the extremely negative mood of society. For most of the war veterans, the symptoms of the "Vietnam War Syndrome" appear with a delay of several months after returning to their homeland. At the same time, the syndrome was mainly diagnosed among those veterans who were socially unsettled (they could not find their place in a peaceful life, get an education, work, ensure their life). And it was formed to a large extent under the influence of awareness of the attitude of society (society) towards them, in an aggressive (by influence on them, their feelings and perception) information environment, which, with a high degree of probability, led to changes 
in their cognitive status and accordingly reduce the resistance of their organisms, the development and deepening of the syndrome.

"Afghan (1979-1989)" and "Chechen (RF 1994-1996)" syndromes had similar manifestations, but almost immediately after the participants of these wars returned to their homeland. This was largely due to the deep socio-economic and political crisis in their country. Attitudes towards them of society and the information background were also uncomfortable.

A feature of the syndrome of the Persian Gulf War is the complex manifestation of PTSD and CMD. Most of the predisposing factors remain the same as in previous wars: this is the "hostile-minded" territory in which the events took place, the specific motivation of the participants in the events and the ambiguous attitude of society towards them. In addition, a priori knowledge of the war, its threats and possible consequences most likely caused the onset of the formation of syndromes, nervous and psychological exhaustion of the participants in the events throughout their participation in them, starting from the moment they were sent to the zone where the events occurred (informational pre-PTSD). With a high degree of probability as a result of high awareness and negative expectations, the resistance of the body of combatants significantly decreased, which may be due to psychosomatic reactions. In addition, according to the recollections of many participants in the events, they were given various unknown vaccinations and were given various, in their opinion, little-studied, preparations. And during the fighting a large number of experimental weapons were used. Including new electronic means, ammunition containing depleted uranium, etc.

But the underlying, common cause in the formation of these syndromes is, as studies have shown, the informational component. The growth of society informatization increases the degree of - both general and targeted - the destructive influence of information on participants in crisis situations, which in turn strengthens and aggravates PTSD, and in some cases is one of the main reasons for its emergence and formation.

Changes in the nature and characteristics of modern wars have a significant impact on the etiology of crisis situations syndromes [27, 28].

First of all, this refers to the features, means and methods of warfare [29, 30].

In present-day military conflicts, with the practical implementation of the elements of the new strategic concepts: "global combat", "asymmetric combat", "network-centric war", "strategic paralysis", "parallel wars", "guided wars", "hybrid wars", "cognitive warfare", "global presence", "global coverage", "proxy wars", etc., there is a steady tendency for their participants to use both experimental and serial high-tech weapons and military equipment (which prevail on the effectiveness of existing mass production samples) and integrated information, psychological, cognitive and cybernetic targeted and random effects on their members [1, 31, 32].

The development and renewal of high-tech weapons of warfare and their use in military conflicts in the late twentieth and early twenty-first centuries have become avalanche-like. So, if in the war on the Korean Peninsula (1950-1953) only 9 previously unknown types of weapons were used, in Vietnam (1964-1975) there were already 25 of these types, in conflicts in the Middle East (1967, 1973, 1982, 1986) about 30 in the war in the Persian Gulf (1991) - 50, then in the conduct of military operations in the Balkans in 1999 over 100 models and weapons systems were used that were not previously used. During military operations in Iraq (March-April 2003), especially in modern military conflicts, the number of innovative high-tech types of weapons and military equipment, especially information, psychological, cybernetic and cognitive influences, is growing exponentially.

At the same time, such means, as a rule, even with their non-mass use, and especially information about them and the peculiarities of their impact on a person and possible consequences, significantly affect the personnel and its moral and psychological state.

Practice shows that in most countries of the world in order to timely respond to the challenges and threats of present and future prevention, containment and neutralize, the defense sector of states includes two main components: deterrence potential, which consists of the traditional types of armed forces and the potential for wars of a new type, which is based on the strength and means of special operations, information and psychological operations, electronic warfare, intelligence, information and analytical support, cyberdefense, operational management of forces and means, 
infocommunication, units equipped with robotic systems and tools to deal with them, and other high-tech manpower and resources.

A hybrid war that is de jure going on the territory of Ukraine, and de facto covers more and more participants around the world [33] in its content, forms and methods of conducting can be considered as a specific variant of the implementation of four-generation wars (English Fourth generation warfare (4GW) - according to the western classification) [34]. That is, the conflict, which is characterized by the erasing of the differences between the immediate war, politics and economy, between the military and civilians involved in the war. These ideas emerged during the Cold War, when it became clear to superpowers that large-scale use of tanks, aircraft and missiles was ineffective in these conditions, and the role of subversive operations (both partisan and political, economic, informational, psychological) increased in quantity and quantity.

Generally, in modern conflicts, the achievement of the goal of aggression usually begins with non-force methods, mainly economic, political, diplomatic, informational, psychological, cybernetic, cognitive, etc. [28, 35].

In whole, in hybrid conflicts of any intensity, hostilities (operations) are a composite of other (non-force) actions mutually coordinated in a single plan and plan that prevail at all their stages (origin, escalation, intensification, attenuation, settling). This creates destabilizing internal and external processes in the state that is the object of aggression (concern and discontent of the population, migration, acts of civil disobedience, etc.). In the future, to achieve strategic goals, methods of conducting actions with large-scale involvement of reconnaissance forces and means, operational control of troops (forces) and means, as well as traditional means of destruction, state armed groups, non-combatants and other participants (terrorists, radical armed groups, mercenaries, partisans), special operations forces, etc. Thus, the hybridity of modern conflicts is based on the possibilities that are a derivative of the high-tech development of mankind. And the hybrid war itself is a high-tech conflict, a continuation of the policies of states (coalitions, political groups, transnational corporations, etc.) with the aim of imposing their will on opponents through complex adaptive and asymmetric synchronized influences on them in different spaces and spheres (Fig. 1) with a combination of conventional and non-conventional components, ensuring multidimensionality, multiplicity and synergy of results and a high level of uncertainty for opponents, flax final objectives and ways to achieve them [35].

Hybrid wars, firstly, are not declared and, secondly, therefore, cannot be completed in the classical sense of the end of wars and military conflicts. This is a kind of permanent war of variable intensity in various areas with chain reactions of interaction, launch and synergistic manifestations of destructive manifestations, in which the entire population of the country and the international community are consciously or unconsciously involved in one degree or another.

The impact is on all spheres of life, on all sectors of society and throughout the state (Fig. 1).

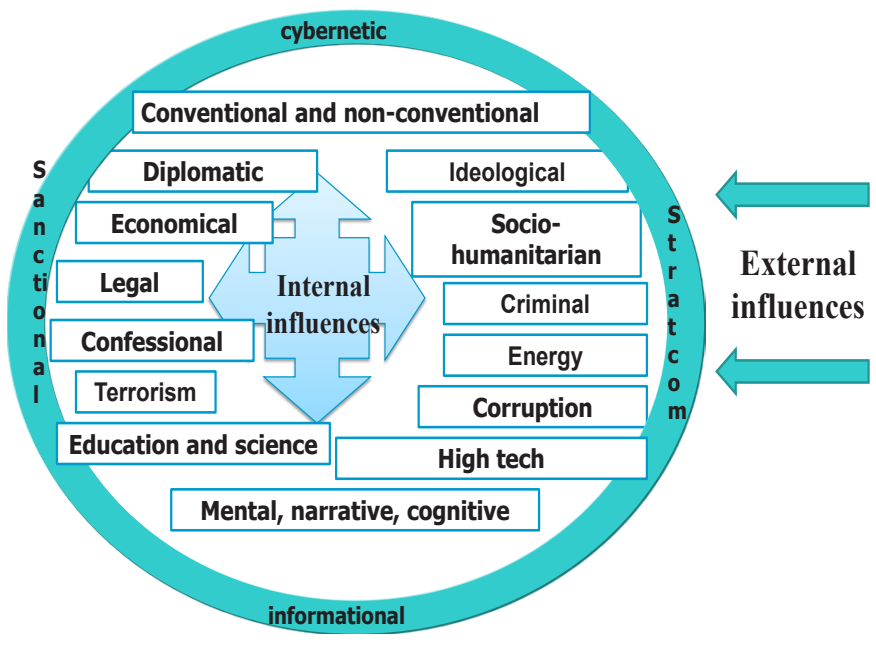

Fig. 1. Spheres of hybrid wars 
Thanks to the use of innovative technologies, it became possible to move from actions of a general destructive nature to actions with a predominantly functional and structural impact on the enemy, and most importantly, attaining a cognitive advantage over him.

Studies have shown that cognitive confrontation has become an integral part of modern and future wars and military conflicts, both interstate and intrastate, and between any geopolitical and regional actors. The cognitive component plays an exceptional role in the aggregate of factors that shape and cause a military conflict, affect its course and result, intensity and consequences. Therefore, modern wars, especially future wars, are fought for the cognitive sphere of society (society, social groups, man) and the management of it (them).

Cognitive influences can be deliberate and random, multi-vector and complex, of a general focus or targeted (targeted), aimed at society as a whole or at specific communities or individuals, to achieve a short-term or long-term effect, immediately or after the latent phase, with or without variation of values etc.

In modern conditions, all parties to the conflict seek to control exactly the cognitive space, covering perception, awareness, belief, understanding and values, the intellectual environment, both of individuals and social groups and society as a whole, in which, in fact, they make decisions. Therefore, the main result of successful cognitive actions is a change in the model of the world and its perception in a person, social groups of society, and society as a whole, which makes it possible to take them under control and exercise external control at the emotional, moral, cultural, ideological and mental levels, with the formation of stable stereotypes for the perception of reality through their prism. Of particular importance are the imposition and promotion of false scientific, social, economic, government, military theories, paradigms, concepts, strategies, narratives that are most effectively promoted and implemented through educational institutions and scientific institutions, electronic, social networks and the blogosphere. For this purpose, all opportunities of strategic communications are used, informational, psychological, cybernetic and other actions (actions, operations, etc.) are carried out, which are aimed at both the direct participants in the conflict and the population of the countries participating in it, the international community. The peculiarity is that even when state actors perform actions in a planned and coordinated manner, they take place against the background of the chaotic target and random similar influences of all other actors. This transforms into an information-cybernetic and cognitive version of the war of "all against all" (in cybernetic, informational and cognitive spaces). As a result, as the conducted studies show, the objects to which cognitive actions are directed can be not only put into a state of cognitive resonance, dissonance or imbalance, but can also receive informational and cognitive injuries, reach the cognitive limits of perception (the impossibility of further safe perception of ), partial or complete cognitive disorientation and even before cognitive collapse, with the subsequent transition to a state of cognitive aggression or frustration in everything, and Atia and depression. That is, to get a stress disorder due to cognitive trauma.

All this became the determining factors forming the hybrid war syndrome, in which practically the entire territory of the country is a zone of active destructive actions of different nature and character.

The consequences of a hybrid war (conflict) are not limited to the number of dead, maimed and destructions. They also include the effects on the cognitive sphere of citizens, social groups and society as a whole. This is due to both direct and indirect influence on the consciousness and subconscious, psycho-physiological, mental state and health of people who both participated in the conflict, and simply stayed in the war zone (the conventional component of the hybrid war) and the entire population countries (partially from other countries) where there is a conflict with the geospatial and other types of differentiation of such influence. At the moment, in the above categories, both combatants and civilians, who find themselves in the hybrid conflict zone, there is a manifestation of a number of characteristic psychological and behavioural characteristics that can be characterized as "hybrid war syndrome" and its derivatives "specific military hybrid war syndrome", "specific PTSD of hybrid warfare" and others. The reasons for the occurrence of such states are the consequences of different levels of threats to life and health, the constant change installation and intensity of combat tension, duration of combat and specific non-combat loads of varying inten- 
sity, often exceeding the limits of human capabilities, loss of comrades, participation in violence against the enemy, which occur in a complex ethno-national situation against the background of intense complex cognitive influences. At the same time, the extent of coverage of the contingent affected by conventional effects is significantly different both in intensity and in other parameters. As a result, the cognitive sphere and the psyche of people exposed to the factors of hybrid conflict of varying intensity and content are transformed in the perception of a peaceful environment (including in a post-hybrid world), standard values of society, and assessments by peaceful citizens of participants in hostilities. In addition, among them there is a stratum of people who have developed a "specific militar syndrome of hybrid war" (readiness and desire to be a participant in crisis situations of a military nature), which is largely due to the low, directly combat (military) intensity of hybrid conflicts and multispectrality unconventional actions in them, as well as those benefits that some participants received during their stay in the area of events, the specificity of changes in their self-esteem and state-of-the-art, cognitive dissonance outside the conflict zone. Such individuals have combat skills that are not applicable in civilian life, they are easily violent. The feeling of their own peculiarity (superiority, exclusivity) formed by the conditions of the hybrid conflict causes in them the development of elements of the so-called horizontal inequality. They have a desire to receive a high level of income (as when taking part in hostilities), but have no desire to learn a profession or to work routinely. They are not inclined, even in the absence of competitive education and qualifications, to work in low-maintenance and low-paying jobs. They are inclined to participate in conflict situations in everyday life in order to achieve their goals and want to receive social and economic benefits from life all at once, and from society unconditional universal respect, and also have a high level of migration mobility that is realized in search of a better life.

Thus, in the formation of a "hybrid war syndrome", the place and time of a crisis situation acquire their own characteristics depending on where conventional or non-conventional actions are conducted, with the prevailing role of informational and psychological influence and cognitive subjective changes among their participants. Therefore, the manifestations of "Syndrome of a Hybrid War" are of a polyetiological nature.

In addition, it is formed both among combatants and non-combatants, which also brings its features into its manifestations. It is the first fully manifested cognitive defeat, as individual subjects and social groups. In addition, also for the first time, relative to other crisis syndromes, social-social group symptoms, the formation of migratory symptoms, the formation of specific PTSDs, etc. are beginning to take place.

Thus, the syndrome of hybrid warfare (hybrid conflict) is a condition manifested as a complex of characteristic mental, psychosomatic, physiological and cognitive changes that occur to varying degrees in the population of countries involved in a hybrid conflict, subjected to a combination of traumatic influences of various nature and a complex of informational and psychological and cognitive influences, having individual and group manifestations.

\section{Conclusions}

1. A partial commonality of the formation and manifestation of various crisis situations syndromes (Vietnamese, Chechen, Afghan, Persian Gulf syndrome, etc.) is established, and on the other hand there is a certain difference in the factors underlying the formation and description of these syndromes, as well as their manifestations.

2. The concept of "Crisis Situation Syndrome" is defined, which allows generalizing different syndromes and at the same time emphasizing the difference between them.

3. The mechanisms and features of the development of the "hybrid war syndrome" are formulated. It has been established that in the formation of the "hybrid war syndrome" the place and time of a crisis situation acquire their own characteristics depending on where conventional or non-conventional actions are conducted, with the prevailing role of informational, mental, cognitive influences and cognitive subjective changes among their participants.

4. The definition of the term "hybrid war syndrome" was given.

5. It has been established that the "hybrid war syndrome" is formed both among combatants and non-combatants, for the first time in it the cognitive impairment of both individual subjects 
and social groups is fully manifested. In addition, for the first time, in relation to other crisis syndromes, there are social-social group symptoms, the formation of migratory symptoms, the formation of specific PTSDs, etc.

6. Developed and described the mechanisms of development and models of PTSD emerging in a hybrid war. Three models of PTSD development are described; the mechanisms of their development, their basic similarities and the differences between them are indicated.

7. The proposed classification of PTSD with the release of "shock-stress", "accumulated stress", combined and "deferred stress".

8. The technology of objective diagnosis, treatment and prevention of PTSD and hybrid war syndrome is proposed, which includes establishing possible etiological factors affecting the formation of crisis states syndromes with differentiation of impact factors, detection itself with the formation of a differentiated approach to treatment, as well as prevention with the development of techniques "maintenance". The technology is based on a comprehensive psychological and ophthalmologic examination.

\section{References}

[1] Telelim, V. M., Danik, Yu. G. et. al.; Telelim, V. M. (Ed.) (2015). Osnovi strategiyi natsionalnoyi bezpeki ta oboroni derzhavi. Kyiv: NUOU im. Ivana ChernyahIvskogo, 620.

[2] Global Conflict Trends. Available at: http://www.systemicpeace.org/conflicttrends.html Last accessed: 20.01.2018

[3] Vetnamskiy sindrom. Available at: http://kak-bog.ru/vetnamskiy-sindrom

[4] Portnov, A. A. (2018). Sindrom Vetnamskoy Voynyi. Available at: https://ilive.com.ua/health/ sindrom-vetnamskoy-voyny_123933i88403.html

[5] Mihalskiy, A. V., Tsarov, Yu. O. (2011). Posttravmatichniy stresoviy rozlad: Istorichniy oglyad. Problemi suchasnoyi psihologiyi, 12, 687-696.

[6] Geyts, R. (2014). Dolg. Memuaryi ministra voynyi. Moscow: AST, 1080.

[7] Soldatkin, V. A. (Ed.) (2015). Posttravmaticheskoe stressovoe rasstroystvo. Rostov na Dony: Izd-vo RostGMU Minzdrava, 624.

[8] Donbasskiy sindrom veteranov «ATO»- pochemu on ne pohozh na Vetnamskiy? Available at: https://t-34-111.livejournal.com/771101.html

[9] Vol. 6: Physiologic, Psychologic, and Psychosocial Effects of Deployment-Related Stress (2008). Gulf War and Health. Washington: The National Academies Press, 75-113. Available at: https://www.nap. edu/read/11922/chapter/7

[10] Drug Addiction in the Military. Available at: https://theoakstreatment.com/ptsd/drug-addiction-military/

[11] Dursa, E. K., Barth, S. K., Schneiderman, A. I., Bossarte, R. M. (2016). Physical and Mental Health Status of Gulf War and Gulf Era Veterans. Journal of Occupational and Environmental Medicine, 58 (1), 41-46. doi: http://doi.org/10.1097/jom.0000000000000627

[12] How Common Is PTSD? Available at: https://www.ptsd.va.gov/understand/common/index.asp

[13] Tull, M. (2018). Rates of Post-Traumatic Stress Disorder in Military Veterans. Available at: https://www.verywellmind.com/rates-of-ptsd-in-veterans-2797430

[14] Diagnoz pocttpavmaticheckoe ctpeccovoe pacctpoyctvo (ptcp). Available at: https://opsihoze. ru/rasstrojstva-lichnosti-i-povedenija/diagnoz-posttravmaticheskoe-stressovoe-rasstrojstvo-ptsr.html

[15] Vol. 8: Update of Health Effects of Serving in the Gulf War (2010). Gulf War and Health. Washington: The National Academies Press. doi: https://doi.org/10.17226/12835

[16] Vol. 3: Fuels, Combustion Products, and Propellants (2005). Gulf War and Health. Washington: The National Academies Press. doi: http://doi.org/10.17226/11180

[17] Proctor, S. P., Heeren, T., White, R. F., Wolfe, J., Borgos, M. S., Davis, J. D. et. al. (1998). Health status of Persian Gulf War veterans: Self-reported symptoms, environmental exposures and the effect of stress. International Journal of Epidemiology, 27 (6), 1000-1010. doi: http://doi.org/10.1093/ije/27.6.1000

[18] Kuveytskie neftyanyie pozharyi. Available at: https://ru.wikipedia.org/wiki/Кувейтские_ нефтяніе_пожарі 
[19] Updated Literature Review of Sarin (2004). Gulf War and Health. Washington: The National Academies Press. doi: http://doi.org/10.17226/11064

[20] Vol. 1: Depleted Uranium, Pyridostigmine Bromide, Sarin, and Vaccines (2000). Gulf War and Health. Washington: The National Academies Press. doi: http://doi.org/10.17226/9953

[21] Vol. 5: Infectious Diseases (2007). Gulf War and Health. Washington: The National Academies Press. doi: http://doi.org/10.17226/11765

[22] Vol. 10: Update of Health Effects of Serving in the Gulf War (2016). Gulf War and Health. Washington: The National Academies Press. doi: http://doi.org/10.17226/21840

[23] Vsplesk samoubiystv sredi amerikanskih soldat: odin suitsid v den. Available at: https:// topwar.ru/15333-vsplesk-samoubiystv-sredi-amerikanskih-soldat-odin-suicid-v-den.html

[24] Umershie ot ubiystv, samoubiystv i nasilstvennoy smerti neustanovlennogo haraktera. Available at: https://lost-kritik.livejournal.com/14150.html

[25] Danyk, Y., Maliarchuk, T. (2015). E-learning Application for Prevention, Detection and Therapy of Posttraumatic Stress Disorder. International Journal of Humanities and Social Science, 5 (9 (1)), 71-76. Available at: http://www.ijhssnet.com/journals/Vol_5_No_9_1_September_2015/7.pdf

[26] Shugaev, G. (2015). Samoubiystva v armii, esli voyuesh ne «Za Rodinu!». Available at: https:// politikus.ru/articles/65062-samoubiystva-v-armii-esli-voyuesh-ne-za-rodinu.html

[27] Danyk, Y., Maliarchuk, T., Kokhreidze, G. (2017). Hybrid highly technological synergy of modern wars and military conflicts. Proceedings of the David Agmashenebeli National Defense Academy of Georgia, 14-21.

[28] Danyk, Y., Hudz, S. (2015). Special operations for disruption of state and military control system. Security and Defence Quarterly. Security and Defence Quarterly, 4 (9), 38-54. Available at: https:// securityanddefence.pl/resources/html/article/details?id=124640 Last accessed: 27.04 .2018

[29] Danyk, Y. (2017). State cyber defense formation and development in conditions of hybrid challenges and threats. 2017 International Conference on Information and Telecommunication Technologies and Radio Electronics (UkrMiCo). doi: http://doi.org/10.1109/ukrmico.2017.8095427

[30] Danik, Yu. G., Grischuk, R. V.; Danik, Yu. G. (Ed.) (2016). Osnovi kibernetichnoyi bezpeki. Zhitomir: ZhNAEU, 636.

[31] Danik, Yu. G., Boychenko, O. S. (2016). Prioritetni visokotehnologichni napryami zabezpechennya oboronozdatnostI derzhavi v umovah zagrozi ta vedennya "gibridnih viyn". Nauka i oborona, 2, 19-27.

[32] Danik, Yu. G., Katkov, Yu. I., Pichugin, M. F. (2006). Natsionalna bezpeka: zapobigannya kritichnim situatsiyam. Zhitomir: Ruta, 388.

[33] Gorbulina, V. P. (Ed.) (2017). Svitova gibridna viyna: ukrayinskiy front. Kyiv: NISD, 496.

[34] Lind, U. S., Naytingeyl, K., Shmitt, D. F., Satton, D. U., Uilson, G. I., Corps Gazette, M. (1989). Menyayuscheesya litso voynyi: chetvertoe pokolenie. Available at: http://topwar.ru/22781-menyayuscheesya-lico-voyny-chetvertoe-pokolenie.html

[35] Danyk, Y., Maliarchuk, T., Briggs, C. (2017). Hybrid War: High-tech, Information and Cyber Conflicts. Connections: The Quarterly Journal, 16 (2), 5-24. doi: http://doi.org/10.11610/connections.16.2.01 